〔酶化 第 40 巻，第 12 号, p. $437 \sim 442,1966$ ]

\author{
感光色素の抗稲白葉枯病菌作用(第 1 報) \\ 化学棈造と抗菌性の関係 \\ 石井至，片桐政子，坂詰偕一郎*，見里朝 正 \\ （農林省農業技術研究所，少西六写真工業株式会社化学研究所） \\ 昭和 41 年 5 月 13 日受理
}

\title{
Antibacterial Effect of Photosensitizing Dyes on Xanthomonas oryzae, Leaf Blight Bacteria of Rice Plant
}

Part I. The Relationship between the Chemical Structure of the Dyes and their Antibacterial Activity

By Itaru ISHII, Masako Katagiri, Kaiichiro SAKazUME* and Tomomasa Misato

National Institute of Agricultural Sciences; *Chemical Research

Laboratories, Konishiroku Shashin Kogyo Co., Ltd.

\begin{abstract}
760 photosensitizing dyes were tested for bactericidal activity in vitro against Xanthomonas oryzae, leaf blight bacteria of rice plant. It was found that 205 dyes, which were cyanine- or styryl-type, were effective for inhibiting growth of $X$. oryzae, four dyes of which at a concentration of $0.1 \mu \mathrm{g} / \mathrm{ml}$ completely inhibited the growth of $X$. oryzae. The relationship between the chemical structure of photosensitizing dyes and their antibacterial activity was discussed. In greenhouse, using rice seedlings inoculated artificially with $X$. oryzae, effect of photosensitizing dyes was tested for control of leaf blight, and it was found that several dyes were highly effectivc. (Received May 13, 1966)
\end{abstract}

\section{緒言}

感光色素の中には抗細菌作用 ${ }^{(1,2)}$, 抗系状菌作用 ${ }^{(3)}$, 駆虫作用 ${ }^{(4)}$ ，植物ホルモン的作用 ${ }^{(5)}$ 等の生物学的作用を 現わするのがり，ての医学的応用に関する研究，化学 構造々抗菌作用との関保についての研究が多数報告され ているが，農薬として使用する面についての研究は未だ 行なわれていない，渚者らは感光色素が稲白葉枯病菌に 対して特に強い殺菌力を有することを知ったので，これ らを稲白葉枯病防除薬剤として使用することを目的とし て研究を行なった. 760 種類の感光色素について抗菌性 を陚験し，その中で 205 種類の色素が有効であることを 知り，化学構造と抗菌性との関係を栲察した。数種類の 色素について温室内稲苗接種試験を行なって，かなりの 稲白葉枯病の防除効果を確かめた，本報ではこれらの結 果について報告する.

\section{実験材料および方法}

（1）微生物：Xanthomonas oryzae H 5809 执よ
び，その他の供試植物病原細菌は農技研病理科保存菌株 を用いた。

（2）感光色菜：感光色素化合物の 760 種類を合成 し，再結晶を繰り返し純度 $100 \%$ に精製したものを試験 に供した，その中で基本的な構造を有する色素の 42 種 類とその融点を第1表に示した。

（3）濾紙円板法による抗菌力の測定法：培地とし て向・渡辺培地 (sodium glutamate $0.2 \%, \mathrm{KH}_{2} \mathrm{PO}_{4}$ $0.2 \%, \mathrm{MgCl}_{2} 0.1 \%, \mathrm{FeSO}_{4} 0.01 \%$, sucrose $2 \%$, 醉

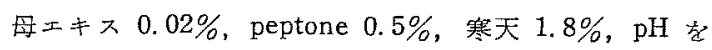
6.8 亿調節) を用いた。 $X$. oryzae を $10 \mathrm{ml}$ 試験管斜面

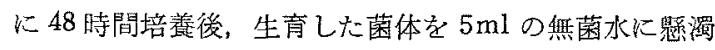
し，その $1 \mathrm{ml}$ を $100 \mathrm{ml}$ の融解寒天培地に稀釈し，これ を上層として流して固めた平面培養調製した，感光色 素を $1,000 \mu \mathrm{g} / \mathrm{ml}$ の濃度で ethanol K溶解し, 直径 8 $\mathrm{mm}$ の濾紙円板に渗みこませて風幹した後，固化直後の 上記平面培地上に置き， $27^{\circ} ， 48$ 時間培養した後，生じ 
第 1 婊 感光色器の Xanthomonas oryzae に対する抗菌力

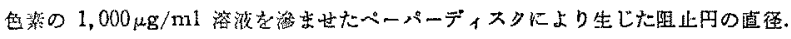

\begin{tabular}{|c|c|c|c|c|c|c|c|c|}
\hline \multirow{2}{*}{$\overbrace{\begin{array}{c}\text { Dye } \\
\text { No. }\end{array}}$} & \multirow[b]{2}{*}{ 梅造式 } & \multirow{2}{*}{ 被 } & \multirow{2}{*}{$\frac{\text { 検 }}{\text { 名 }}$} & \multirow{2}{*}{ 感 } & \multicolumn{2}{|l|}{ 色 } & \multicolumn{2}{|c|}{ 抗 蕃力 } \\
\hline & & & & & 称 & m.p. & 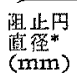 & 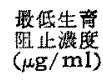 \\
\hline 1 & (I) & \multicolumn{4}{|c|}{$1^{\prime}$-methyl-1-ethyl-4'-pyrido-2-cyanine iodide ${ }^{(6)}$} & $212^{\circ}$ & 34 & 1.3 \\
\hline 2 & (II) & \multicolumn{4}{|c|}{2 (p-dimethylaminostyryl) pyridine methyl perchlorate ${ }^{(12)}$} & $257^{\circ}$ & 32 & 0.6 \\
\hline 3 & (III) & \multicolumn{4}{|c|}{$1,1^{\prime}$-dimethyl-2,2'-cyanine iodide ${ }^{(6)}$} & $245 \sim 6^{\circ}$ & 33 & 0.3 \\
\hline 4 & (IV) & \multicolumn{4}{|c|}{$1^{\prime}$-methyl-1-ethyl-2, $2^{\prime}$-cyanine iodide ${ }^{(6,8)}$} & $258 \sim 9^{\circ}$ & 31 & 0.3 \\
\hline 5 & (v) & \multicolumn{4}{|c|}{$1,1^{\prime}$-dimethyl-2'-pyrrolino-2-cyanine iodide( ${ }^{(6)}$} & $245 \sim 6^{\circ}$ & 37 & 1.3 \\
\hline 6 & $(\mathrm{VI})$ & \multicolumn{4}{|c|}{$1^{\prime}$-methyl-1-ethyl-2-pyrrolino-2-cyanine iodide ${ }^{(6,7)}$} & $205^{\circ}$ & 23 & 1.3 \\
\hline 7 & (VII) & \multicolumn{4}{|c|}{$1,1^{\prime}$-diethyl-5-methyl-2'-pyrrolino-2-cyanine iodide ${ }^{(6)}$} & $195^{\circ}$ & 20 & 10 \\
\hline 8 & (VIII) & \multicolumn{4}{|c|}{$1,1^{\prime}, 3^{\prime}, 3^{\prime}$-tetramethyl-indo-2-cyanine perchlorate ${ }^{(6,7)}$} & $256^{\circ}$ & 27 & 5 \\
\hline 9 & (IX) & \multicolumn{4}{|c|}{ 1-methyl-3'-ethyl-thiazolino-2-cyanine iodide ${ }^{(6)}$} & $190 \sim 2^{\circ}$ & 43 & 0.3 \\
\hline 10 & $(\mathrm{x})$ & \multicolumn{4}{|c|}{$1,3^{\prime}, 4^{\prime}$-trimethyl-thiazolo-2-cyanine iodide ${ }^{(6)}$} & $243^{\circ}$ & 35 & 0.1 \\
\hline 11 & (XI) & \multicolumn{4}{|c|}{$1,3^{\prime}, 4^{\prime}$-trimethyl-thiazolo-2-azamethinecyanine iodide ${ }^{(21,22)}$} & $232^{\circ}$ & 44 & 0.3 \\
\hline 12 & (XII) & \multicolumn{4}{|c|}{$\begin{array}{r}1,3^{\prime} \text {-dimethyl-4'-phenyl-thiazolo-2-azamethine- } \\
\text { cyanine iodide }{ }^{(21,23)}\end{array}$} & $274^{\circ}$ & 46 & 0.1 \\
\hline 13 & (XIII) & \multicolumn{4}{|c|}{ 1-ethyl-3, $4^{\prime}$-dimethy 1 -thiazolo-2-cyanine iodide ${ }^{(6,14)}$} & $238 \sim 9^{\circ}$ & 34 & 0.3 \\
\hline 14 & (XIV) & \multicolumn{4}{|c|}{ 1-ethyl-3'-n-octyl-4'-methyl-thiazolo-2-cyanine iodide(6) } & $166 \sim 8^{\circ}$ & 18 & 2.5 \\
\hline 15 & (XV) & \multicolumn{4}{|c|}{ 1-3'-dimethyl-thia-2-azamethinecyanine iodide ${ }^{(21)}$} & $270^{\circ}$ & 45 & 0.3 \\
\hline
\end{tabular}

第 1 表の撒造式 $(I) \sim(X V)$<smiles></smiles>

(I)<smiles>CCCN1C(=Cc2ccc3ccccc3[n+]2[I-])C=Cc2ccccc21</smiles>

(IV)<smiles></smiles>

(VII)<smiles>[3H][n+]1c(C=C2C=Cc3ccccc3N2C)sc2ccccc21</smiles>

(X)<smiles></smiles>

(XIII)<smiles>CN(C)c1ccc(C=Cc2cccc[n+]2C(C)(Cl)Cl)cc1</smiles>

(II)<smiles>[3H][n+]1c(C=C2CCCN2C)ccc2ccccc21</smiles><smiles>CN1C(=CC2=[N+](C)c3ccccc3C2(C)C)C=Cc2ccccc21</smiles>

(VIII)<smiles>[3H][n+]1c(/N=c2\ccc3ccccc3n2C)sc(-c2ccccc2)c1C</smiles>

(XI)

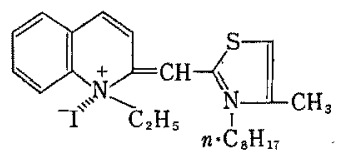
(XIV)<smiles>[3H][N+]1([3H])C(C=C2C=Cc3ccccc3N2C)=CCc2ccccc21</smiles>

(III)<smiles></smiles>

(VI)<smiles>CCSC(=C1C=Cc2ccccc2N1C)[N+](C)(C)C(C)CC</smiles>

(IX)<smiles></smiles>

(XII)<smiles></smiles>

(XV) 
第 1 淕つづき

\begin{tabular}{|c|c|c|c|c|c|c|c|c|c|}
\hline \multirow[b]{2}{*}{$\begin{array}{l}\text { Dye } \\
\text { No. }\end{array}$} & \multirow[b]{2}{*}{ 踭邀式 } & \multirow[t]{2}{*}{ 被 } & \multirow{2}{*}{$\frac{\text { 湌 }}{\text { 名 }}$} & \multirow{2}{*}{ 光 } & \multirow{2}{*}{\multicolumn{2}{|c|}{ 色聚 }} & \multirow[b]{2}{*}{ m.p. } & \multicolumn{2}{|c|}{ 抗荤力 } \\
\hline & & & & & & & & 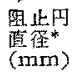 & 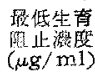 \\
\hline 16 & (XVI) & \multicolumn{5}{|c|}{ 1-methyl-3'-ethyl-thia-2-cyanine iodide $(6,7)$} & $255 \sim 7^{\circ}$ & 21 & 0.3 \\
\hline 17 & (XVIr) & \multicolumn{5}{|c|}{$1,2^{\prime}, 4^{\prime}$-trimethyl-1 $1^{\prime}, 3^{\prime}, 4^{\prime}$-oxadiazolo-2-cyanine iodide $(6,7,18)$} & $266 \sim 7^{\circ}$ & 26 & 5 \\
\hline 18 & (XVIII) & \multicolumn{5}{|c|}{$1,4^{\prime}$-dimethyl-2'-ethyl-1 $1^{\prime}, 3^{\prime}, 4^{\prime}$-thiadiazolo-2-cyanine iodide ${ }^{(6)}$} & $259 \sim 60^{\circ}$ & 48 & 0.3 \\
\hline 19 & $(\mathrm{XIX})$ & \multicolumn{6}{|c|}{$4(p$-dimethylaminostyryl) quinoline $n$-propyl iodide $(12,17)$} & 30 & 1.3 \\
\hline 20 & $(\mathrm{Xx})$ & \multicolumn{5}{|c|}{$\begin{array}{r}1^{\prime}, 3,3^{\prime}, 3^{\prime} \text {-tetramethyl-10-phenoxy-selenoindo- } \\
\text { carbocyanine iodide(13) }\end{array}$} & $235^{\circ}$ & 20 & 1.3 \\
\hline 21 & $(\mathrm{XXI})$ & \multicolumn{5}{|c|}{$\begin{array}{r}\text { 2-(p-dimethylaminostryl)-3,3-dimethyl-indolenine } \\
\text { methyl iodide(12) }\end{array}$} & $238^{\circ}$ & 33 & 1.3 \\
\hline 22 & $(\mathrm{XXII})$ & \multicolumn{5}{|c|}{$2-\left(p\right.$-dimethylaminostyryl) oxazoline methyl iodide ${ }^{(12,15)}$} & $216 \sim 8^{\circ}$ & 27 & 20 \\
\hline 23 & (XXIII) & \multicolumn{5}{|c|}{$3,3^{\prime}$-dimethyl-oxacyanine iodide $(6,19)$} & $310^{\circ}$ & 32 & 1.3 \\
\hline 24 & (XXIV) & \multicolumn{5}{|c|}{$3,3^{\prime}$-dimethyl-oxacarbocyanine iodide ${ }^{(9)}$} & $278^{\circ}$ & 27 & 1.3 \\
\hline 25 & $(\mathrm{XXV})$ & \multicolumn{5}{|c|}{ 2-(2-benzopyranylidene methyl) benzoxazole ethyl iodide(10) } & $250 \sim 1^{\circ}$ & 29 & 40 \\
\hline 26 & (XXVI) & \multicolumn{5}{|c|}{$\begin{array}{l}1,1^{\prime} \text {-diisopropyl-3, } 3^{\prime} \text {-dimethyl-5, } 5^{\prime} \text {-dichloro- } \\
\text { benzimidazolocarbocyanine iodide }\end{array}$} & $252^{\circ}$ & 23 & 5 \\
\hline 27 & $(\mathrm{XXVII})$ & \multicolumn{5}{|c|}{$3,3^{\prime}, 10$-trimety1-thiazolino-thiacarbocyanine iodide $(13,16)$} & $225^{\circ}$ & 31 & 0.3 \\
\hline 28 & $(\mathrm{XXVHI})$ & \multicolumn{5}{|c|}{ 2-(2-benzopyranylidene methyl) -thiazoline ethyl iodide ${ }^{(10)}$} & $229 \sim 30^{\circ}$ & 22 & 5 \\
\hline 29 & $(\mathrm{XXIX})$ & \multicolumn{5}{|c|}{$3,3^{\prime}, 4,4^{\prime}$-tetramethyl-thiazolocyanine iodide $\mathrm{e}^{(0)}$} & $320^{\circ}$ & 45 & 0.3 \\
\hline 30 & $(\mathrm{Xxx})$ & \multicolumn{5}{|c|}{$3,3^{\prime}$-diethy $1-4,4^{\prime}$-dimethyl-thiazolocyanine iodide ${ }^{(6)}$} & $310^{\circ}$ & 21 & 1.3 \\
\hline
\end{tabular}

第 1 㳖の權造式 (XVI) （XXX)<smiles>CCC[n+]1c(C=C2C=Cc3ccccc3N2C)sc2ccccc21</smiles>

(XVI)<smiles>Cc1n[n+](C)c(C=C2C=Cc3ccccc3N2C)o1</smiles>

(XVII)<smiles>[R4]OC(=CC=C1N(C)c2ccccc2C1(C)C)c1[se]c2ccccc2[n+]1[I-]</smiles>

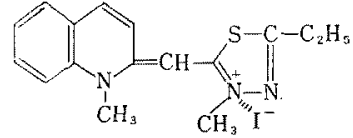

(XVII)<smiles></smiles>

(XXXI)<smiles></smiles>

(XXIV)

(XXII)<smiles>CN1C(=CC2Oc3ccccc3[N+]2(C)[I-])Oc2ccccc21</smiles>

(XXIII)<smiles>[3H][n+]1c(C=CC2N(C)c3cc(Cl)ccc3N2C(C)C)n(C(C)C)c2ccc(Cl)cc21</smiles><smiles></smiles>

(XXVIII)<smiles></smiles>

(XXIX)<smiles>CCN1C(=Cc2scc(C)[[Y]+]2([I-])CC)SC1C</smiles>

$(\mathrm{XXX})$ 
第 1 茭つゔき

\begin{tabular}{|c|c|c|c|c|c|c|c|c|c|}
\hline \multirow[b]{2}{*}{$\begin{array}{l}\text { Dye } \\
\text { No. }\end{array}$} & \multirow[b]{2}{*}{ 集遥式 } & \multirow{2}{*}{ 被 } & \multirow[b]{2}{*}{ 名 } & \multirow{2}{*}{ 光 } & \multirow{2}{*}{\multicolumn{2}{|c|}{$\frac{\text { 色 }}{\text { 称 }}$}} & \multirow[b]{2}{*}{ m. p. } & \multicolumn{2}{|c|}{ 抗菌力 } \\
\hline & & & & & & & & 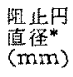 & 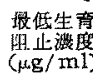 \\
\hline 31 & $(\mathrm{XXXI})$ & $3,3^{\prime}-\mathrm{di}-n$-but & $-4,4^{\prime}$-dimet & yl-th & zoloc & anine iodide $(6,24)$ & $248 \sim 9^{\circ}$ & 25 & 1.3 \\
\hline 32 & $(\mathrm{XXXII})$ & $3,3^{\prime}$-di-n-hex & 1-4, $4^{\prime}$-dimet & $y 1-t h$ & zoloc & ranine iodide $\mathrm{e}^{(6)}$ & $235 \sim 6^{\circ}$ & 22 & 2.5 \\
\hline 33 & (XXXIII) & $3,3^{\prime}$-di-n-hept & $1-4,4^{\prime}-$ dime & $y 1-t$ & azolo & yanine iodide ${ }^{(6)}$ & $223^{\circ}$ & 12 & 2.5 \\
\hline 34 & (XXXIV) & $3,3^{\prime}-\mathrm{di}-n$-octy & $-4,4^{\prime}$-dimet & $1-$ thi & oloc & anine iodide $(\theta)$ & $226 \sim 7^{\circ}$ & 10 & 2.5 \\
\hline 35 & $(\mathrm{XXXV})$ & $3,3^{\prime}$-di-n-non & $1-4,4^{\prime}$-dimet & $y 1-t h$ & zoloc & ranine iodide ${ }^{(6)}$ & $242 \sim 3^{\circ}$ & 10 & 2.5 \\
\hline 36 & $(\mathrm{XXXVI})$ & $3,3^{\prime}-\mathrm{di}-n$-dode & $y l-4,4^{\prime}-\operatorname{dim}$ & hyl- & iazol & cyanine iodide $(6)$ & $229 \sim 30^{\circ}$ & 0 & 20 \\
\hline 37 & (XXXVII) & $3,3^{\prime}$-dimethyl- & -phenyl-thi & zolo- & ame & $\begin{array}{l}\text { ine- } \\
\text { thiacyanine iodide(21) }\end{array}$ & $272^{\circ}$ & 45 & 0.1 \\
\hline 38 & (XXXVIII) & $2,3,4,4^{\prime}$-tetra & thyl-thia & $\begin{array}{l}0-1^{\prime}, \\
\text { thiad }\end{array}$ & $\begin{array}{l}4^{\prime}- \\
\text { zoloc }\end{array}$ & anine perchlorate $e^{(6)}$ & $230 \sim 2^{\circ}$ & 42 & 0.6 \\
\hline 39 & (XXXIX) & 2 -ethyl-3 $3^{r}, 4-d$ & methyl-1, 3 , & thia & zalo & thiacyanine iodide $e^{(6)}$ & $281 \sim 2^{\circ}$ & 48 & 0.1 \\
\hline 40 & $(\mathrm{XI})$ & 2 -(2-benzopyr & nylidene me & hy1) - & nzot & iazole ethyl iodide $e^{\{10\}}$ & $320^{\circ}$ 以上 & 25 & 0.3 \\
\hline 41 & (XLI) & $2,2^{\prime}, 4,4^{\prime}-$ tetr & methyl-1, 3 , & thia & zolo & $\begin{array}{l}\text { anine } \\
\text { perchlorate }\{6,20\}\end{array}$ & $223 \sim 5^{\circ}$ & 41 & 1.3 \\
\hline 42 & (XLII) & 2-(2-benzopyr & nylidene m & hyl) & enzos & $\begin{array}{l}\text { lenazole } \\
\quad \text { ethyl iodide }{ }^{(10)}\end{array}$ & $300^{\circ}$ 以上 & 24 & 0.3 \\
\hline 対 & 照 & & streptomy & & & & 一 & 29 & 10 \\
\hline
\end{tabular}

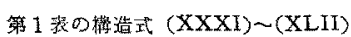<smiles></smiles>
XXXI)

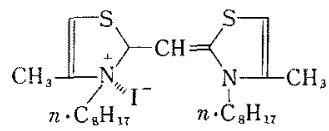

(XXXIV)<smiles>[3H][n+]1c(/N=c2\sccn2C)sc2ccccc21</smiles>
(XXXVII)<smiles></smiles>

(XL)

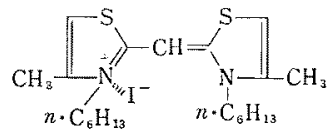
(XXXII)

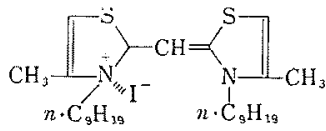

( $\times X \times V)$<smiles></smiles>

(XXXVIII)<smiles></smiles>

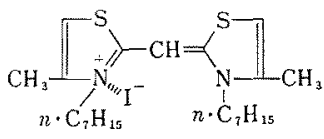

(XXXIII)<smiles></smiles>

(XXXVI)

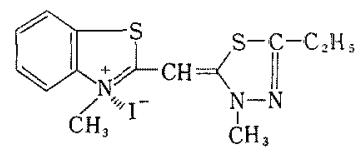

(XXXIX)<smiles>[3H][N+]1(CC)C(/C=C2\C=Cc3ccccc3O2)=[Se]c2ccccc21</smiles>

(XLII)
た阳止円を测定した。

（4）最低生亩阻止濃度の測定法：向・渡辺培地の $10 \mathrm{ml}$ 試験管液体培地飞感光色菜の所定濃度を溶解させ X. oryzae の斜面培盖の 1 白金耳支接種し，48時間振㑼 培養した後，生壳の有無を調べた。
（5）抗囷スベクトラムの測定法：寒天稀釈塗抹法 によって測定を行なったＸ. oryzae 以外の細菌の場合 は，ブイヨン寒天培地を用いた。細囷の斜面培竸か、ら 1

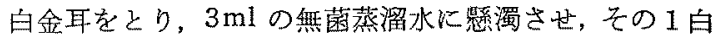
猃耳をとり，色亚の所定濃度を溶解させて固めた培地上 
に塗抹し， 24 時間または 48 時間培養を行ない，その生 育の有無を調べた。

（6）温室内稲苗接種試験法：稲の品種は十石を用

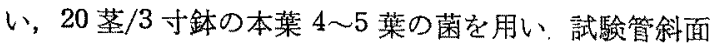

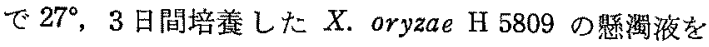
上位 2 葉に単針接種し, 接種夰日にターンテーブル上で スプレーガンを使用して展盖郕を加用した感光色素の水 溶液を散布 $(40 \mathrm{ml} / 3$ 針) し，風乾後ガラス温室内に置い た. 1 処理は 3 鉢とし，接種 21 日後に葉位別に病斑長 を測定し，防除価を算出した。

\section{実験結果および考察}

760 種類の感光色素について濾紙円板法を用いで， $X$. oryzae に刘する阻止円の直佳を測定し，その中て轨菌 力の高い色素については，さらに最低生育阻止濃度を测 定した. その結果 205 種類の色菜が抗菌性を有し35 種 類の色素が streptomycin 以上の抗菌力を有することが 確かめられた。第 1 表に，抗菌力の高い色素の中で代表 的な基本構造を有する色素とその抗菌力を示した，抗菌 性学有する色素は cyanine 色素, styryl 色菜の系統で あり，構造の中に carbonyl 点含色素，4級窒素を含 まない色素は全く抗菌生を示さなかった。結果を総括し て述べると以下のとおりでめる。

4 級窒素を含む複素複核と 3 級窒素を含さ複素環核, aminostyry] 棈造, benzopyran 核とをそれぞれ methine 鎖で連結した型の色素が有効であった，有効な複素環の 種類は, pyridine, quinoline, pyrroline, indolenine, oxazoline, benzoxazole, benzimidazole, thiazoline, thiazole, benzothiazole, benzoselenazole, oxadiazole, thiadiazole でめった，第1表に示した色素の各種の基

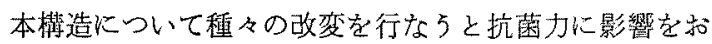
よぽした。

Methine 鎖については methine と azamethine では 差は魝くまた monomethine と trimethine では差は 無いが, pentamethine 色素は概して抗菌力が小で， heptamethine 色素は全く無効であった，抗菌力につい ては複素環窒素結合 alkyl が重要な因子であり，一般に $\mathrm{N}-\mathrm{CH}_{3}$ は N-C $\mathrm{H}_{5}$ 上り抗藩力が大で, No. $29 \sim \mathrm{No} .36$ の色素で見られるよ5に alkyl 炭素数の多い色菜はやや

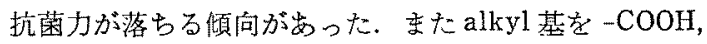
$-\mathrm{SO}_{\mathrm{g}} \mathrm{H},-\mathrm{OH},-\mathrm{CN}$ で置換すると抗菌力を減少するか， 生たは失った，色菜の酸根は halogen が良く、 dimethyl一 sulfate, diethylsulfate, toluenesulfonate は抗菌性老 低下させた。複素環の種類, aminostyryl の組合好と抗 菌性の関係については，明らかな傾向は認かられなかっ t.

X. oryzae 以外の細菌に対する抗菌力を数種類の感光 色素について試験した結果を第2 表に示した。これらの 色素がいずれ女 X.oryzae に対して特異的な効力そ有す のは興味樑いことである。

数種類の感光色素について温室内で稻白葉枯病の防除 試試を行なった結果を第 3 表に示した。いずれの色菜も 防除效果学示したが, No. 14, No. 29, No. 33, No. 34, No. 35, No. 36 は効果が高く, cellocidin 製剂の効果に 这敵した。また防除効果は in vitro の抗菌力とは逆に alkyl 基の炭素数の多い方が高い傾向を示した。

第 2 表 感光色美の各種細菌に対する抗菌力

\begin{tabular}{|c|c|c|c|c|c|c|}
\hline & \multicolumn{6}{|c|}{ 色素の最低生育阻止渋度 } \\
\hline & No. 29 & No. 21 & No. 24 & No. 25 & No. 40 & No. 42 \\
\hline Agrobact. tumefaciens & 100 & & & & & \\
\hline Erwinia aroidae & 100 & & & & & \\
\hline Pseudomonas eriobotryae & 100 & & & & & \\
\hline P. fluorescens & $>100$ & & & & & \\
\hline P. solanacearum & $>100$ & & & & & \\
\hline P. tabaci & 10 & 100 & 100 & $>100$ & $>100$ & 100 \\
\hline Xanthomonas citri & & 100 & 100 & 100 & 100 & 100 \\
\hline$X$. oryzae & $>1$ & 10 & 10 & 100 & $<1$ & $<1$ \\
\hline$X$. pruni & 100 & $>100$ & $>100$ & $>100$ & $>100$ & $>100$ \\
\hline Bacillus subtilis & 100 & & & & & \\
\hline Escherichia coli & $>100$ & & & & & \\
\hline Staphylococcus aureus & 100 & & & & & \\
\hline
\end{tabular}


筙 3 表 感光色罢に上る稻白葉枯病防除效果

\begin{tabular}{|c|c|c|c|c|c|}
\hline \multirow{2}{*}{ 薬 } & \multirow{2}{*}{$\begin{array}{l}\text { 散有藞度 } \\
(\mu \mathrm{g} / \mathrm{ml})\end{array}$} & \multicolumn{3}{|c|}{ 楼位别病斑長 (mm) } & \multirow{2}{*}{$\begin{array}{c}(\%) \\
(\%) \text { 䧈 }\end{array}$} \\
\hline & & 4 莯 & 5 淎 & 平均 & \\
\hline No. 14 & 200 & 15 & 25 & 20 & 75 \\
\hline No. 14 & 400 & 9 & 16 & 13 & 84 \\
\hline No. 31 & 200 & 24 & 43 & 34 & 57 \\
\hline No. 31 & 400 & 23 & 27 & 25 & 68 \\
\hline No. 32 & 200 & 27 & 31 & 29 & 63 \\
\hline No. 32 & 400 & 34 & 37 & 35 & 54 \\
\hline No. 33 & 200 & 21 & 24 & 23 & 71 \\
\hline No. 33 & 400 & 7 & 23 & 15 & 81 \\
\hline No. 34 & 200 & 20 & 30 & 25 & 68 \\
\hline No. 34 & 400 & 11 & 18 & 15 & 81 \\
\hline No. 35 & 200 & 12 & 24 & 18 & 77 \\
\hline No. 35 & 400 & 10 & 12 & 11 & 86 \\
\hline No. 36 & 200 & 13 & 20 & 17 & 78 \\
\hline No. 36 & 400 & 11 & 15 & 13 & 84 \\
\hline $\begin{array}{l}\text { 七ロサイ } \\
\text { 水和剂 }\end{array}$ & 150 & 13 & 13 & 13 & 84 \\
\hline 無爸理 & - & 84 & 73 & 79 & - \\
\hline
\end{tabular}

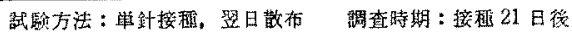

籍品程: 十石

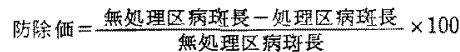

$$
\text { 要約 }
$$

760 種数の感光色素について稲白䒚枯病菌に対する in vitro の抗菌力を試験した結果，205 種類の色素が有效 で耑った。その中で 4 種類の色素は $0.1 \mu \mathrm{g} / \mathrm{ml}$ の鼬度で Xanthomonas oryzae の生育を完全に阻止した，有効で

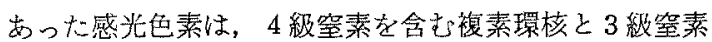
を含さ複菜環核， benzopyran 核，aminostyryl 構造と をそれ品れ methine 鎖で連結した型の色素であった。

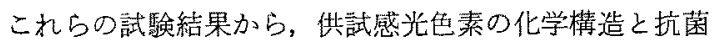
性の関保について考察を行なった。 また温空内で稻白葉 枯病防除試験を行なった結果，数種類の感光色素が高い 防除效果を示した。

本報告の要旨は昭和 41 年度日本㦈芸化学会大会にお

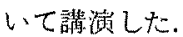

(1) C. H. Browning, J. B. Cohen, F. R. S., S. Ellingworth, R. Gulbransen : Proc. Roy. Soc., B 96, 317 (1924).

(2) C. H. Browning, J. B. Cohen, F. R. S., S. Ellingworth, R. Gulbransen : ibid., B 100, 293 (1926).

(3) M. Pianka, J. C. Hall : J. Sci. Food. Agric., 8, 432 (1957).

(4) E. Bueding:Ann. N. Y. Acad. Sci., 50, 115 (1948).

(5) T. Ogata, M. Shingu : Proc. Japan Acad., 25, 22 (1950).

(6) I. G.: B.P. 423, 792 (1932) ; O. Fischer: Ber., 35, 3677 (1902) ; S. Gabriel, C. F. V. Hirsch : Ber., 29, 2610 (1896).

(7) O. Doebner : Ber., 25, 2072 (1892); A. Hofmann : Ber., B 21, 1236, 1238 (1880).

(8) F. M. Hammer : J. Chem. Soc., 1928, 206.

(9) M. A. Phillips : ibid., 1930, 2685 ; 尾形輝太 郎：理化学研究所糫報, 13, 6 (1934).

(10) H. Meerwein : Ann., 641, 1 (1961); H. Meerwein et al : Ber., 89, 2060 (1956).

(11) E. K.: U.S. P. 2, 739, 149 (1956) ; F. E. King, J. W. Clark-Lew is : J. Chem. Soc., 1953, 172.

(12) J. L. B. Smith : ibid., 123, 2288 (1923) ; E. Fischer: Ann., 236, 116 (1886).

(13) L. G. S. Brooker: U. S. P. 2, 478, 366 (1949).

(14) A, Hantzsch : Ann., 250, 262 (1889).

(15) M. Bergmann, E. Brand : Ber., 56, 1280 (1923).

(16) L. M. Clark : J. Chem. Soc., 1928, 2319.

(17) K. N. Campbell, I. J. Schaffner : J. Am. Chem. Soc., 67, 86 (1945).

(18) R. Stollé : Ber., 32, 797 (1899).

(19) N. Fischer: J. Chem. Soc., 1930, 2502.

(20) C. T. S. Hofman : J. Prakt. Chem., [2] 53 (1835).

(21) T. D. Keudoll : B. P. 447,038 (1934), B. P. 447, 109 (1934).

(22) J. R. Byers: Org. Synth., 19, 10 (1939).

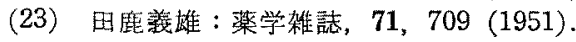

(24) E. R. Buchmann : J. Org. Chem., 6, 764 (1941). 